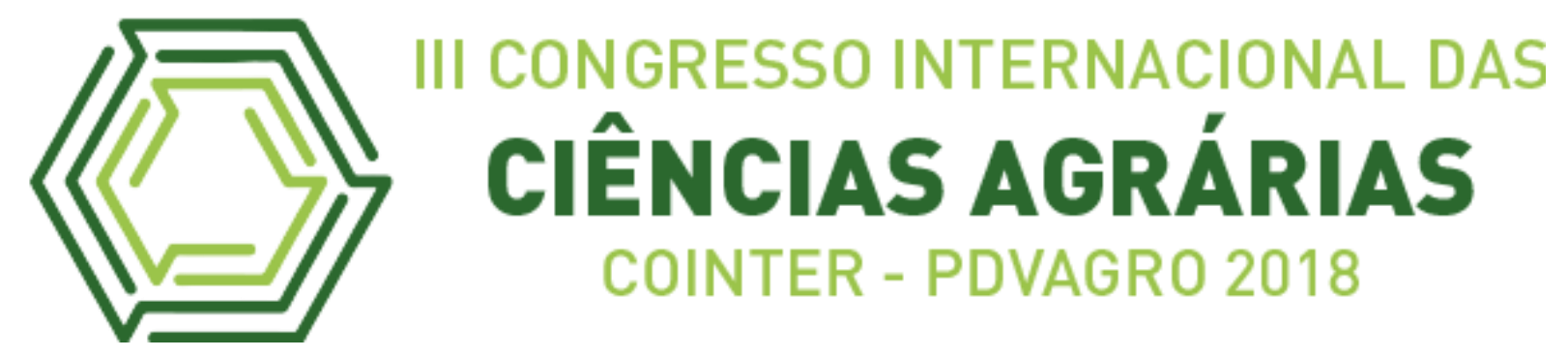

\title{
MELHORAMENTO PARTICIPATIVO: RESGATANDO, PRESERVANDO E MULTIPLICANDO SEMENTES CRIOULAS
}

\section{PARTICIPATORY IMPROVEMENT: REDUCING, PRESERVING AND MULTIPLYING CRIOUL SEEDS}

Apresentação: Relato de Experiência

\begin{abstract}
Madson Rafael Barbalho da Silva ${ }^{1}$; Abraão Rodrigues de Almeida ${ }^{2}$; Jane Clésia Silva
\end{abstract} dos Santos ${ }^{3}$; Alciele da Silva Leite ${ }^{4}$ José Carlos da Costa

\section{DOI: https://doi.org/10.31692/2526-7701.IIICOINTERPDVAGRO.2018.00747}

\section{Introdução}

É notável os avanços produtivos que o Melhoramento Genético de Plantas (MGP) tradicional proporcionaram para produtores rurais do mundo todo, mas o que percebe-se, é que ao longo desse desenvolvimento, essas técnicas só surtiram efeito em ambientes que se mostraram favoráveis, com solos férteis, água adequada e condições edafoclimáticas que permitissem o livre caminho para uma resposta produtiva dessas lavouras trabalhadas. No entanto, o mesmo não ocorreu com os produtores localizados em ambientes menos favoráveis e que não dispunham de recursos para a aquisição de insumos (geralmente produtores de países em desenvolvimento), refletindo na baixa adoção de cultivares modificadas geneticamente pelos mesmos, visto que não podiam arriscar a substituição de suas tradicionais, conhecidas e confiáveis variedades locais, as chamadas sementes crioulas.

O melhoramento participativo é um componente do manejo da diversidade genética das plantas que, por sua vez, consiste no resgate, avaliação, caracterização, seleção e conservação dos recursos genéticos. Ambas as estratégias, melhoramento participativo e manejo, desempenham importante função em comunidades de agricultura familiar onde são comuns os problemas relacionados à fertilidade dos solos e a estresses nutricionais, entre outras limitações ambientais. O trabalho tem como objetivo evidenciar os benefícios que as praticas do melhoramento participativo promovem para a manutenção da diversidade genética

\footnotetext{
${ }^{1}$ Agronomia, IFPE, madsonbarbalhoagronomo@gmail.com

${ }^{2}$ Agronomia, IFPE, abraaoalmeida98@gmail.com

${ }^{3}$ Agronomia, IFPE, janecslia28@gmail.com

${ }^{4}$ Agronomia, IFPE, alcieleleite@gmail.com

${ }^{5}$ Dr. em Melhoramento Vegetal, IFPE, jose.costa@vitoria.ifpe.edu.br
} 
vegetal.

\section{Relato de Experiência}

Esse trabalho é fruto do projeto de extensão intitulado MELHORAMENTO PARTICIPATIVO: UTILIZAÇÃO DO MÁXIMO POTENCIAL GENÉTICO DAS PLANTAS DE FORMA SUSTENTÁVEL.

Com a dificuldade da produção em solos consideráveis problemáticos, fez-se necessário a elaboração de cultivares consideráveis superiores em produção, adaptação e produtividade. Em meados dos anos 70 quando, em função da crise energética, houve a necessidade de se reavaliar e alterar os princípios e as práticas que constituíam os fundamentos da agricultura industrializada, percebeu-se então, que a mudança fundamental seria representada pela evidência crescente de que o germoplasma vegetal teria uma tendência maior ao lançamento de materiais que respondesse mesmo em condições adversas.

Nessa premissa é que adotamos como metodologia fazer o levantamento das comunidades rurais e assentamentos, que preservam, armazenam e utilizam variedades crioulas na mesorregião zona da mata de Pernambuco. Após a identificação das localidades contempladas com o projeto, ocorreu a elaboração de uma cartilha sobre a importância da preservação genética das variedades crioulas e os mecanismos de reprodução das plantas cultivadas por esses povos, pois grande parte desconhece os mecanismos de polinização das espécies cultivadas e que o uso de híbridos e cultivares melhoradas ou transgênicas nas proximidades de suas propriedades podem interferir na preservação das sementes crioulas, sendo necessário realizar o isolamento das espécies.

Foram realizados encontros nas comunidades rurais e assentamentos que detinham cultivares crioulas e junto aos mesmos ocorreu a distribuição da cartilha, no qual simultaneamente ocorria a capacitação dos mesmos (seminários, oficinas), abordando temas relacionados aos sistemas reprodutivos das plantas, formas de propagação, forma de isolamento para evitar contaminação com pólen e mecanismos de resgate das cultivares locais.

Todos os acessos que foram coletados dos agricultores foram submetidos ao plantio no nosso campus, afim de sucessivas avaliações para criação de um banco de germoplasma in lоси. Esses materiais foram implementados no campo e continuamente são feitos trabalhos científicos e divulgação desses dados obtidos em eventos (seminários, congressos, feiras, etc.) nacionais relacionados a área. Atualmente estamos trabalhando com acessos de pimenta, 
feijão, fava e milho com experimentos implantados no IFPE e no município de Moreno - PE.

Imagem 1: Coleta de diferentes materiais de pimenta de Agricultores de Vicência - PE. Fonte: Própria

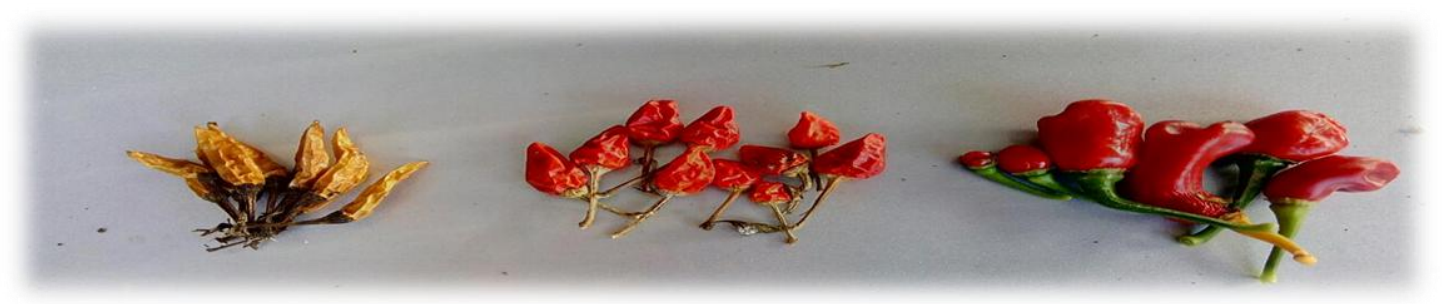

Imagem 2: Coleta de diferentes materiais de milho, feijão e fava de Agricultores Itaquitinga - PE. Fonte: Própria

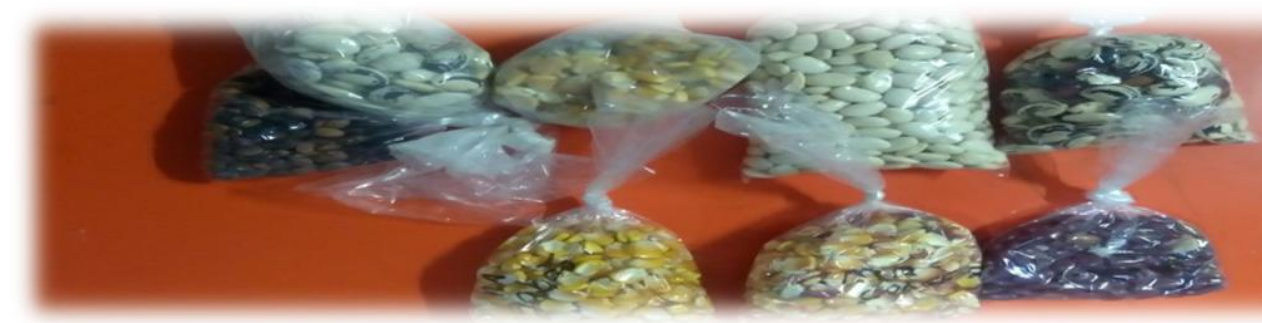

Imagem 3: Avaliação do potencial germinativo das diferentes espécies de pimentas locais comparada com um material comercial. Fonte: Própria 


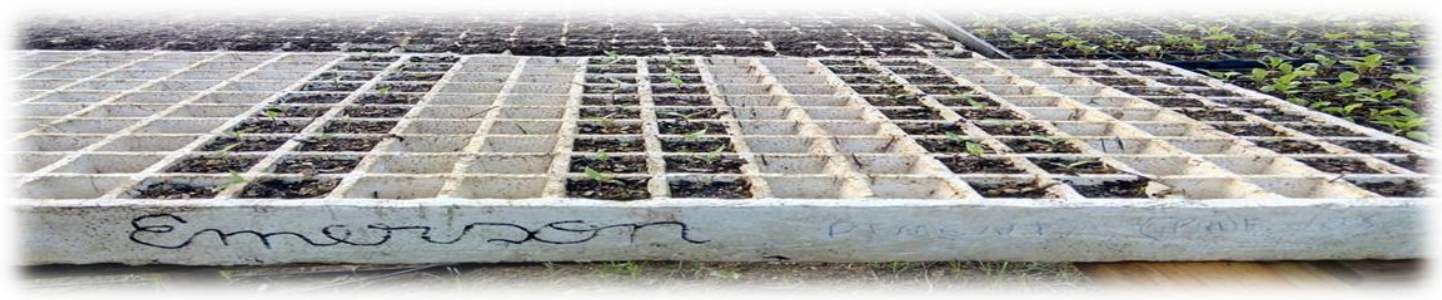

Imagem 4: Análise biométrica das sementes (tamanho, diâmetro, largura e peso). Fonte: Própria

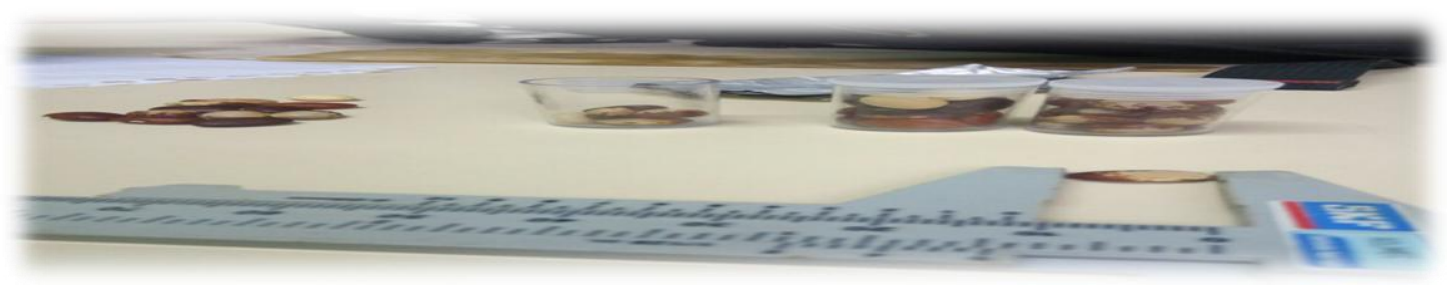

Imagem 5 Plantio do material coletado no PAIS - IFPE Campus Vitória de Santo Antão. Fonte: Própria

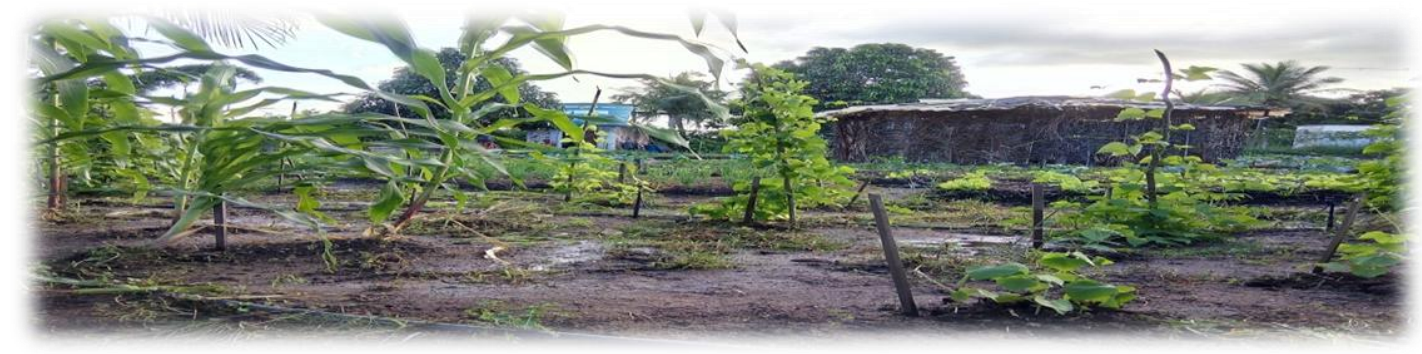

\section{Considerações}

Mediante as contribuições parciais que o projeto vem trazendo possa vir a perpetuar a importância da manutenção, armazenamento e distribuição das sementes locais, contribuindo assim para uma produção segura de alimentos e preservando a identidade cultural e consequentemente a variabilidade genética.

\section{Referências}

BUENO, L. C. S.; MENDES, A. N. G.; CARVALHO, S. P. Melhoramento genético de plantas: princípios e procedimentos. Lavras: UFLA, 2001. 282 p.

CECARELLI, S. Main stages of a plant breeding programme. In: CECARELLI, S.; GUIMARÃES, E. P.; WELTZIEN, E. (Ed.). Plant breeding and farmer participation. Roma: FAO, 2009. p. 6374.

GOMES, J. C. C.; BORBA, M. A moderna crise dos alimentos: oportunidades para a agricultura familiar? Agroecologia e Desenvolvimento Rural Sustentável, v.3, p.52, 2000. 
MACHADO, A.T. Construção do melhoramento genético de plantas: do convencional ao participativo. Revista Brasileira de Agroecologia. v. 9, n.1, p.3550, 2014. 